\title{
Adalimumab in ankylosing spondylitis: an evidence- based review of its place in therapy
}

\author{
Stephanie Hennigan, Christoph Ackermann, Arthur Kavanaugh
}

Center for Innovative Therapy, Division of Rheumatology, Allergy and Immunology, University of California, La Jolla, California, USA

\begin{abstract}
Introduction: Ankylosing spondylitis (AS) is an idiopathic chronic inflammatory disease that has prominent effects on the spine and peripheral joints. In addition, extraarticular manifestations such as enthesitis and acute anterior uveitis may be clinically important. In recent years, the therapy of AS has changed, largely due to the introduction of inhibitors of the proinflammatory cytokine tumor necrosis factor (TNF). Adalimumab, a human monoclonal antibody specifically for TNF, is the most recent of the TNF blocking agents that have been approved for the treatment of active, nonsteroidal antiinflammatory drug (NSAID)-refractory patients with AS.
\end{abstract}

Aims: To evaluate the evidence for the therapeutic value of adalimumab in ankylosing spondylitis.

Evidence review: There is clear evidence that adalimumab, administered $40 \mathrm{mg}$ subcutaneously every 2 weeks, substantially improves the signs and symptoms of NSAID-refractory, active AS when compared with placebo treatment. There is ample evidence that adalimumab causes significant improvements in physical health status and overall AS-specific, health-related quality of life and physical functioning, which consequently leads to better work productivity. There is substantial evidence that adalimumab improves spinal and sacroiliac joint inflammation in AS patients. Initial results from clinical trials suggest that there is no increased risk of serious infections or malignancies in adalimumab-treated patients with AS. The most common adverse events were injection-site reactions. Limited economic evidence suggests that adalimumab $40 \mathrm{mg}$ may be cost effective when used according to current valid treatment guidelines.

Place in therapy: Adalimumab is an effective treatment for patients with active AS.

Core Evidence. 2008;2(4):295-305

Key words: adalimumab, ankylosing spondylitis, TNF inhibitor, evidence, treatment

Core evidence place in therapy summary for adalimumab in ankylosing spondylitis

\begin{tabular}{|c|c|c|}
\hline Outcome measure & Evidence & Implications \\
\hline \multicolumn{3}{|l|}{ Patient-oriented evidence } \\
\hline Quality of life & Substantial & Adalimumab improves quality of life, physical functioning, and work productivity \\
\hline Tolerability & Clear & Adalimumab has an acceptable tolerability profile \\
\hline \multicolumn{3}{|l|}{ Disease-oriented evidence } \\
\hline ASAS criteria & Clear & $\begin{array}{l}\text { Adalimumab produces significant improvement after } 24 \text { weeks; improvement is maintained for up to } \\
2 \text { years }\end{array}$ \\
\hline BASDAI criteria & Clear & $\begin{array}{l}\text { Adalimumab produces significant improvement after } 24 \text { weeks; improvement is maintained for up to } \\
2 \text { years }\end{array}$ \\
\hline Remission & Clear & Adalimumab produces partial remission for up to 2 years \\
\hline $\begin{array}{l}\text { Spinal and sacroiliac joint } \\
\text { inflammation measured by MRI }\end{array}$ & Substantial & Adalimumab reduces inflammation for up to 1 year \\
\hline \multicolumn{3}{|l|}{ Economic evidence } \\
\hline Cost effectiveness & Limitied & $\begin{array}{l}\text { Adalimumab is a cost-effective treatment for AS compared with conventional therapy, however, high } \\
\text { acquisition costs remain a concern }\end{array}$ \\
\hline
\end{tabular}




\section{Scope, aims, and objectives}

Ankylosing spondylitis (AS) is a chronic inflammatory disease of the spine and the peripheral joints. AS is mostly characterized by pain and stiffness of the spine, but many patients can have large- joint arthritis, enthesitis, and progressive deformities that often lead to significant disability if left untreated. Until recently, therapeutic options have been relatively limited for patients with AS. Conventional treatment options include nonpharmacologic modalities such as physiotherapy, and nonsteroidal antiinflammatory drugs (NSAIDs). For patients with peripheral arthritis, a class of drugs also used for patients with rheumatoid arthritis (RA), commonly referred to as disease-modifying antirheumatic drugs (DMARDs), has been tried in AS. Although these modalities may have some effect on pain and other symptoms, none of these drugs have been shown to alter the progression of the disease, particularly for spinal disease. A major change in the therapeutic approach to AS came with the introduction of inhibitors of tumor necrosis factor (TNF). To date, three TNF inhibitors have proven to have efficacy in the treatment of AS patients with active NSAID-refractory disease, and demonstrated improvements in signs and symptoms, magnetic resonance imaging (MRI) assessments, and in measures of functional status and quality of life (QOL). Adalimumab (Humira ${ }^{\circledR}$, Abbott), a human monoclonal antibody that binds specifically to TNF, is the most recent of the TNF blocking agents that have been approved for AS in 2006, both in Europe and the US. The objective of this article is to review the clinical evidence base for the use of adalimumab specifically for AS.

\section{Methods}

The English language medical literature was searched in August 2007 in the following databases. The search strategy was "adalimumab in ankylosing spondylitis" for articles published from January 1990 to July 2007 (inclusive). Nonhuman and invitro studies were excluded from the search.

- PubMed, http://www.ncbi.nlm.nih.gov

- EMBASE, http://www.datastarweb.com

- BIOSIS, http://www.datastarweb.com

- National Institute for Health and Clinical Excellence (NICE), http://www.nice.org.uk

- York University Centre for Reviews and Dissemination databases, http://www.york.ac.uk/inst/crd/crddatabases.htm

- NHS Health Technology Assessment Programme, http://www.hta.nhsweb.nhs.uk

- Cochrane Database of Systematic Reviews (CDSR), http://www.cochrane.org/index.htm

- EULAR, http://www.abstracts2view.com/eular/sessionindex.php
A total of 77 publications (excluding guidelines) were identified from the search strategy (Table 1). Following the search and manual checking of the references, 17 full papers and 15 meeting abstracts were included in the evidence base.

\section{Table 1 | Evidence base included in the review}

\begin{tabular}{|llc|}
\hline Category & Number of records \\
\cline { 2 - 3 } & Full papers & Abstracts \\
\hline Initial search & 77 & 53 \\
records excluded & 49 & 38 \\
records included & 13 & 15 \\
Additional studies identified & 4 & 0 \\
Level 1 clinical evidence & 4 & 1 \\
(systematic review, meta analysis) & 3 & 6 \\
Level 2 clinical evidence (RCT) & 3 & 4 \\
Level $\geq 3$ clinical evidence & 4 & 4 \\
$\quad$ trials other than RCT & 4 & 0 \\
$\quad$ case studies & 0 & 0 \\
Economic evidence & 2 & 15 \\
Total records included & 17 & \\
\hline For definitions of levels of evidence, see Editorial Information on inside back cover or on \\
Core Evidence website (http://www.coremedicalpublishing.com). \\
RCT, randomized controlled trial. & & \\
\hline
\end{tabular}

\section{Disease overview}

AS is a chronic inflammatory rheumatic disease typically affecting the sacroiliac joints and the axial skeleton. The hallmark of AS is inflammation of the sacroiliac joints, followed by inflammation rising along the spine leading to back pain and progressive stiffness. This is accompanied by the formation of syndesmophytes (bone outgrowths of the spine). Enthesitis, or inflammation of the entheses (the site of insertion of ligaments, tendons, and other tissue into bone), is another typical feature of AS that can contribute to new bone development and joint fixation (ankylosis). Arthritis of extraaxial joints, in particular the hips, shoulders, and knees, can also lead to progressive deformities and disability. Associated extraarticular manifestations include acute anterior uveitis, cardiovascular and pulmonary abnormalities, neurologic sequelae, and both clinical and subclinical gastrointestinal (Gl) findings.

AS is considered the prototypical condition among a group of related conditions known as the spondyloarthropathies (SpA); others include reactive arthritis, enteropathic arthritis, psoriatic arthritis with axial involvement, undifferentiated spondyloarthritis, and juvenile spondyloarthropathy. Although symptoms can occur at any stage of life, AS typically affects young adults with a peak age of onset between 20 and 30 years. AS is the most frequent subtype of $\mathrm{SpA}$, being more prevalent than previously thought, with an estimated prevalence as high as $1 \%$ in Caucasians and approximately $0.5 \%$ among the general population (Sieper et al. 2006). The presence of HLA-B27 is strongly associated with AS; for example, it is found in about $95 \%$ of patients with AS in the 
US, Europe, and China (Feltkamp et al. 2001). Moreover, there is an association of AS and HLA-B27 in most other ethnic groups worldwide.

The clinical course of AS is variable and is typically characterized by mild or moderate flares of active disease, alternating with periods of near or total quiescence. While some patients have mild impairment that adequately responds to mild therapeutic interventions, others can have a severe disease with spinal fusion, progressive deformities, and pronounced incapacity. Evidence is growing that even in its less severe form, many affected patients manifest significant radiographic joint damage, functional impairment, reduced QOL, and long-term work disability (Chorus et al. 2003; van Denderen et al. 2005).

The societal and economic burden of AS can be considerable. Due to a general occurrence in the third decade of life, the age at which many individuals are developing their maximal earning ability, in combination with the progressive nature of the disease, particularly in cases of continuous disease activity, AS often impairs functional ability and leads to increasing disability and loss of employment. High disease activity and poor physical function have been identified as important determinants of costs (Boonen 2006).

In recent years, advances in the understanding of immunemediated disorders, combined with progress in biotechnology, have led to the development of novel therapeutic agents. These so-called biologic agents, particularly the inhibitors of the proinflammatory cytokine TNF, have proven to be highly effective in patients with AS. The success of these agents has fundamentally altered the clinical approach to patients. In addition to their positive effects on signs and symptoms of AS, TNF inhibitors may offer positive impacts on the societal and economic burden of the disease.

\section{Current therapy options}

Until the introduction of biologics, therapeutic options for AS patients were relatively limited. As with all forms of arthritis, the primary treatment goals for AS include reduction in pain, improvement of function and mobility, psychosocial functioning, and enhancement in overall QOL. These objectives are sought in all AS patients using both pharmacologic and nonpharmacologic modalities.

Various criteria have been used to assess clinical response in AS. The Bath AS Disease Activity Index (BASDAl) consists of six questions measuring the severity of fatigue, spinal pain, peripheral joint pain, tenderness, and stiffness on a visual analog scale (VAS) (0-10). A >50\% improvement in BASDAl is considered clinically relevant.

The ASsessment in Ankylosing Spondylitis International Working Group criteria or ASAS20 response criteria are now used more often (Brandt et al. 2004). An ASAS20 responder is defined as a patient experiencing improvement of at least $20 \%$ and an absolute improvement of at least 1 unit (on a $0-10$ scale) compared with baseline in at least three of the following four domains, with no deterioration (defined as a worsening of at least $20 \%$ or an absolute increase of at least 1 unit) in the remaining domain: patient's global assessment of disease activity as assessed by a VAS; patient's assessment of pain represented by a total back pain score as assessed by VAS; patient function as assessed by the Bath Ankylosing Spondylitis Functional Index (BASFI) score (VAS) (Calin et al. 1994); and inflammation, represented most frequently by the mean of the severity and duration of morning stiffness as assessed by questions five and six of the BASDAI score (VAS). Similarly, the ASAS40 response represents improvement of at least $40 \%$ and an absolute improvement of at least 2 units compared with baseline in at least three of the four domains of the ASAS20 criteria, with no deterioration in the remaining domain. These indices have demonstrated adequate reliability, validity, and responsiveness to change.

NSAIDs have been proven efficacious, in both short-term and extended treatment, in improving the signs and symptoms of AS in multiple randomized controlled trials (RCTs). Therefore, NSAIDs continue to be a mainstay of therapy. A recent review pooling results of four NSAID trials indicated that NSAIDs were superior to placebo in improving spinal pain, peripheral arthritis, and function in AS patients over a 6-week period (Zochling et al. 2006a). Although a number of NSAIDs have been tested, no single agent has proven more advantageous than another in head-to-head trials. Comparable effectiveness in the alleviation of spinal pain and improvement in function has been documented with cyclooxygenase-2 (COX-2) selective inhibitors (Zochling et al. 2006a). The effect of these drugs on peripheral arthritis in AS patients has not been studied directly.

Alternative therapies, such as DMARDs, which are successful in the treatment of other autoimmune arthritides such as RA, offer minimal benefit in the treatment of AS as regards spinal involvement. In the majority of RCTs, low-dose methotrexate had no effect in patients with AS with predominantly axial manifestations (Chen et al. 2006). A more recent, open-label trial also demonstrated nonsignificant improvement in ASAS20 score, physician-performed spinal pain score, QOL, and patient and physician global assessments with higher doses of methotrexate (Haibel et al. 2007a). In the same study, a subgroup of patients with peripheral arthritis did report a decrease in the number of swollen joints, but again the results were not significant.

The role of sulfasalazine in the treatment of AS has been controversial. A recent Cochrane systematic review of RCTs concluded that sulfasalazine may have some benefit in reducing erythrocyte sedimentation rate (ESR, which may correlate with disease activity in AS) and decreasing spinal stiffness, but no evidence of benefit in pain, spinal mobility, physical function, or patient and physician global assessment (Chen \& Liu 2006). This was also validated in patients with early AS $(<5$ years' disease duration), although a small subset of patients did report improvement in inflammatory back pain (Braun et al. 2006a). Although sulfasalazine appears to play little role in suppressing 
axial symptoms in AS, there is some evidence of improvement in peripheral arthritis (Kirwan et al. 1993). In an extended 3-year study, AS patients had significantly fewer episodes of peripheral arthritis during therapy with sulfasalazine compared with placebo. A larger trial examining patients with AS, psoriatic arthritis, and reactive arthritis showed no benefits with sulfasalazine in manifestations of axial disease but a significant response in peripheral arthritis compared with placebo (Clegg et al. 1999).

An open-label trial of leflunomide in AS patients did exhibit significant improvement in peripheral arthritis (Haibel et al. 2005). However, the number of patients was small $(n=10)$ and no significant changes in axial symptoms or other clinical parameters (patient and physician global assessment, QOL) were demonstrated. In a randomized, placebo-controlled trial, leflunomide failed to achieve a $20 \%$ response rate as recommended by the ASAS working group (van Denderen et al. 2005). In addition, no significant differences in peripheral arthritis were seen in the leflunomide group compared with placebo.

The bisphosphonate pamidronate has been investigated in AS with conflicting results. RCTs in NSAID-refractory patients have shown greater improvement in spinal pain and function at a dose of $60 \mathrm{mg}$ versus $10 \mathrm{mg}$ (Maksymowych et al. 2002). The study was not adequately powered to confirm the effect of pamidronate on peripheral arthritis and no further studies have yet examined this as a primary outcome.

Thalidomide has been tried in patients with severe, refractory AS. In a 6-month, open-label trial, the mean BASDAI score and inflammatory markers, C-reactive protein (CRP) and ESR, significantly decreased with thalidomide therapy (Wei et al. 2003). A second study also demonstrated significant improvement $(>20 \%)$ in four of seven primary indices at 1 year (Huang et al. 2002). However, a high incidence of side effects including dizziness, dry mouth, nausea, and headache has limited the use of thalidomide.

Physiotherapy is clearly beneficial for AS patients and should be incorporated early in treatment. However, a standardized exercise protocol has not been established and current studies illustrate a variety of therapy combinations that have shown effectiveness. For example, one RCT examined the effect of a 3-week spa exercise program followed by group physiotherapy versus group physiotherapy alone (van Tubergen et al. 2001). At 12 weeks, patient function in the spa-treated group was significantly better compared with patients who only received group physiotherapy.

TNF blockade has proven successful in the treatment of AS. The first two TNF inhibitors approved for use in AS were etanercept, a dimeric fusion protein of the TNF receptor linked to the Fc portion of human IgG1, and infliximab, a chimeric monoclonal antibody specific for TNF. Pooled results from RCTs have confirmed substantial improvement in spinal pain and function with both etanercept and infliximab (Zochling et al. 2006a). Moderate to significant improvements were also documented in peripheral arthritis, morning stiffness, enthesitis, chest expansion, ESR, and CRP.

\section{Unmet needs}

Although some traditional treatments for AS have established efficacy, not all AS patients show benefit. In a cross-sectional study, more than $20 \%$ of AS patients reported insufficient pain control with NSAIDs, and more than $40 \%$ required a change of NSAID due to lack of efficacy (Zochling et al. 2006b). Furthermore, multiple side effects associated with NSAIDs have limited their use. In the study by Zochling et al. (2006b), more than half of treated patients reported adverse events. GI and cardiac toxicity remain the greatest safety concerns. Gl toxicity appears to be dose-dependent, and symptoms can range from mild diarrhea and dyspepsia to severe GI bleeding or peptic ulceration (Lewis et al. 2002). Although the absolute risk is low, the cardiovascular toxicity of NSAIDs and COX-2 inhibitors has been an area of intense discussion (Solomon et al. 2005).

An important unmet need as regards the optimal treatment of AS is that quite a number of patients suffer the disease for long periods of time, in many cases years, before the diagnosis is established. This substantial delay in diagnosis of AS remains problematic. As a result, many patients already have structural damage at presentation (Khan 2002). This is important as recent studies suggest that patients treated with TNF inhibitors at earlier stages of disease may have better responses to therapy and, therefore, less disease progression (Rudwaleit et al. 2004). An additional concern noted during treatment with other TNF inhibitors is that therapy does not lead to long-term treatmentfree remission. Thus, the majority of AS patients who achieve good control of the signs and symptoms of disease while on a TNF inhibitor and who then stop therapy typically need to restart therapy, often in as little as 1.5-4.5 months after initially stopping (Brandt et al. 2003; Baraliakos et al. 2005). Finally, MRI has shown significant improvement in spinal inflammation in patients with AS treated with TNF inhibitors (Haibel et al. 2006a). However, evidence of the impact of adalimumab and other TNF inhibitors on structural changes or disease progression by MRI has yet to be fully delineated.

\section{Clinical evidence with adalimumab in AS}

\section{Clinical outcomes}

There is clear evidence from clinical trials that treatment with adalimumab significantly improves disease-associated outcomes in AS.

\section{Improvement in ASAS criteria}

Clinical response to adalimumab in AS has most often been evaluated using the ASAS20 response criteria (Brandt et al. 2004). ASAS40 response criteria have also been used. Other validated parameters include the ASAS5/6 response criteria (Brandt et al. 2004), which were developed for clinical trials and used initially in trials of TNF inhibitors. The ASAS5/6 require at least $20 \%$ improvement in five of six domains: spinal mobility as assessed by the Bath Ankylosing Spondylitis Metrology Index (BASMI) (other instruments may be used) (Jenkinson et al. 1994); CRP 
level; and the four domains included in the ASAS20 response criteria. Although the ASAS5/6 criteria are commonly utilized, the clinical advantage of a $20 \%$ improvement in these additional domains remains unclear (van der Heijde et al. 2005). Therefore, it has been recommended that the ASAS40 criteria continue to be assessed in conjunction with the ASAS5/6.

The significant improvement in AS patients with the use of TNF inhibitors has also led researchers to institute criteria for higher levels of response or "partial remission." Partial remission is defined as a value of $<2$ on a $0-10$ scale in each of the four domains of the ASAS20 (Anderson et al. 2001). It is important to note however, that the criteria were developed on the basis of clinical trials with NSAIDs and although validated against expert opinion, may not be as clinically relevant if applied to response with TNF inhibitors (Zochling \& Braun 2006).
The effectiveness of adalimumab in achieving ASAS responses was first investigated in a small, open-label trial of 15 patients with moderate to severe disease over a 52-week period (Haibel et al. 2006a). Of the 13 patients who completed the study, 67\% achieved an ASAS40 response at 52 weeks (Table 2). Extension of treatment with adalimumab to 2 years in this group of patients resulted in persistent levels of ASAS40 response (Haibel et al. 2006b).

The success of the original open-label study lead to larger, more stringent double-blind, placebo-controlled, randomized clinical trials (Tables 2 and 3). The multicenter study Adalimumab Trial Evaluating Long-term Efficacy and Safety in Ankylosing Spondylitis (ATLAS) compared placebo with a subcutaneous injection of adalimumab $40 \mathrm{mg}$ every other week for 24 weeks (van der Heijde et al. 2006a). The primary efficacy

Table 2 | Efficacy of adalimumab in patients with AS based on ASAS and BASDAI criteria

\begin{tabular}{|c|c|c|c|c|}
\hline Outcome & Reference & Design & Treatment & Results \\
\hline \multirow{4}{*}{$\begin{array}{l}\text { BASDAI (>50\% } \\
\text { improvement) }\end{array}$} & Haibel et al. 2006a & OL, 52 wk, 15 pts & Ada 40 mg qow & $>50 \%$ \\
\hline & Haibel et al. 2006b & OL, 104 wk extension, 15 pts & Ada 40 mg qow & $67 \%$ \\
\hline & \multirow[t]{2}{*}{ van der Heijde et al. 2006a } & \multirow[t]{2}{*}{ DBPCRCT, 24 wk, 315 pts } & \multirow{2}{*}{$\begin{array}{l}\text { Ada } 40 \text { mg qow } \\
\text { vs placebo }\end{array}$} & Ada: $42.3 \%^{a}$ \\
\hline & & & & Placebo: $15 \%$ \\
\hline \multirow[t]{13}{*}{ ASAS20/ASAS40 } & \multirow[t]{2}{*}{ Haibel et al. 2006a } & \multirow[t]{2}{*}{ OL, 52 wk, 15 pts } & \multirow[t]{2}{*}{ Ada 40 mg qow } & 73\% (ASAS20); \\
\hline & & & & $67 \%$ (ASAS40) \\
\hline & \multirow[t]{2}{*}{ Haibel et al. $2006 b$} & \multirow[t]{2}{*}{ OL, 104 wk extension, 15 pts } & \multirow[t]{2}{*}{ Ada 40 mg qow } & 73\% (ASAS20); \\
\hline & & & & $60 \%$ (ASAS40) \\
\hline & \multirow[t]{2}{*}{ van der Heijde et al. 2006a } & \multirow[t]{2}{*}{ DBPCRCT, 24 wk, 315 pts } & \multirow[t]{2}{*}{$\begin{array}{l}\text { Ada } 40 \mathrm{mg} \text { qow vs } \\
\text { placebo }\end{array}$} & $\begin{array}{l}\text { Ada: } 51 \%(\text { ASAS20)a } ; 39.4 \% \\
\left(^{(A S A S 40)^{a}}\right.\end{array}$ \\
\hline & & & & $\begin{array}{l}\text { Placebo: } 18 \% \text { (ASAS20); 13.1\% } \\
\text { (ASAS40) }\end{array}$ \\
\hline & \multirow[t]{2}{*}{ van der Heijde et al. 2007b } & \multirow{2}{*}{$\begin{array}{l}\text { DBPCRCT, } 24 \text { wk, } 11 \text { pts TSA } \\
\text { subgroup }\end{array}$} & \multirow{2}{*}{$\begin{array}{l}\text { Ada } 40 \text { mg qow } \\
\text { vs placebo }\end{array}$} & Ada: $100 \%$ (ASAS20); 50\% (ASAS40) \\
\hline & & & & Placebo: 0\% (ASAS20); 0\% (ASAS40) \\
\hline & van der Heijde et al. $2007 a$ & $\begin{array}{l}\text { DBPCRCT, } 104 \text { wk extension, } 315 \text { pts } \\
\text { all switched to OL at } 24 \text { wk }\end{array}$ & $\begin{array}{l}\text { Ada } 40 \mathrm{mg} \text { qow } \\
\text { vs placebo }\end{array}$ & Ada: 79\% (ASAS20); 67\% (ASAS40) \\
\hline & \multirow[t]{4}{*}{ Haibel et al. 2007b } & \multirow[t]{4}{*}{$\begin{array}{l}\text { DBPCRCT, } 12 \text { wk with OL extension } \\
\text { to } 20 \text { wk, } 46 \text { pts with early AS }\end{array}$} & \multirow[t]{4}{*}{$\begin{array}{l}\text { Ada } 40 \mathrm{mg} \text { qow } \\
\text { vs placebo }\end{array}$} & $\begin{array}{l}12 \text { wk Ada: } 68 \% \text { (ASAS20); 54\% } \\
\text { (ASAS40) }\end{array}$ \\
\hline & & & & $\begin{array}{l}12 \text { wk placebo: } 21 \% \text { (ASAS20); } 12 \% \\
\text { (ASAS40) }\end{array}$ \\
\hline & & & & $\begin{array}{l}20 \text { wk Ada: } 68 \% \text { (ASAS20); } 45 \% \\
\text { (ASAS40) }\end{array}$ \\
\hline & & & & $\begin{array}{l}20 \text { wk placebo switched to OL Ada: } \\
71 \% \text { (ASAS20); 58\% (ASAS40) }\end{array}$ \\
\hline \multirow[t]{5}{*}{ ASAS5/6 } & \multirow[t]{4}{*}{ van der Heijde et al. 2006a } & \multirow[t]{4}{*}{ DBPCRCT, 24 wk, 315 pts } & \multirow{4}{*}{$\begin{array}{l}\text { Ada } 40 \mathrm{mg} \text { qow } \\
\text { vs placebo }\end{array}$} & 24 wk Ada: $44.7 \%$ \\
\hline & & & & 24 wk placebo: $12.3 \%$ \\
\hline & & & & 24 wk Ada in pts with TSA: $75 \%$ \\
\hline & & & & 24 wk placebo in pts with TSA: $0 \%$ \\
\hline & van der Heijde et al. 2007a & $\begin{array}{l}\text { DBPCRCT, } 104 \text { wk extension, } 11 \text { pts } \\
\text { TSA subgroup }\end{array}$ & $\begin{array}{l}\text { Ada } 40 \text { mg qow } \\
\text { vs placebo }\end{array}$ & Ada: $38 \%$ \\
\hline
\end{tabular}

a $P<0.001$ vs placebo.

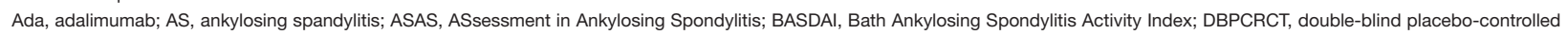
randomized clinical trial; OL, open-label; pts, patients; qow, every other week; TSA, total spinal ankylosis; wk, week. 
Table 3 | Efficacy of adalimumab in patients with AS based on partial remission rates

\begin{tabular}{|c|c|c|c|}
\hline Reference & Design & Treatment & Results \\
\hline $\begin{array}{l}\text { Haibel et } \\
\text { al. } 2007 b\end{array}$ & $\begin{array}{l}\text { DBPCRCT, } 12 \text { wk with } \\
\text { OL extension to } 20 \text { wk, } \\
46 \text { pts with early AS }\end{array}$ & $\begin{array}{l}\text { Ada } 40 \mathrm{mg} \\
\text { qow }\end{array}$ & $\begin{array}{l}12 \text { wk Ada: } 22.7 \% \\
12 \text { wk placebo: } 0 \% \\
20 \text { wk Ada: } 22.7 \% \\
20 \text { wk placebo } \\
\text { switched to OL Ada: } \\
41.7 \%\end{array}$ \\
\hline $\begin{array}{l}\text { van der } \\
\text { Heijde et } \\
\text { al. } 2006 a\end{array}$ & $\begin{array}{l}\text { DBPCRCT, } 24 \text { wk, } \\
315 \text { pts }\end{array}$ & $\begin{array}{l}\text { Ada } 40 \mathrm{mg} \\
\text { qow vs } \\
\text { placebo }\end{array}$ & $\begin{array}{l}24 \text { wk Ada: } 22.1 \% \\
24 \text { wk placebo: } \\
5.6 \% \\
24 \text { wk Ada in pts } \\
\text { with TSA: } 0 \% \\
24 \text { wk placebo in pts } \\
\text { with TSA: } 0 \%\end{array}$ \\
\hline $\begin{array}{l}\text { van der } \\
\text { Heijde et } \\
\text { al. } 2007 a\end{array}$ & $\begin{array}{l}\text { DBPCRCT, } 104 \text { wk } \\
\text { extension, } 315 \text { pts all } \\
\text { switched to OL at } 24 \text { wk }\end{array}$ & $\begin{array}{l}\text { Ada } 40 \mathrm{mg} \\
\text { qow vs } \\
\text { placebo }\end{array}$ & $\begin{array}{l}\text { Ada: } 39 \% \\
\text { Placebo: } 0 \%\end{array}$ \\
\hline $\begin{array}{l}\text { van der } \\
\text { Heijde et } \\
\text { al. } 2007 \mathrm{~b}\end{array}$ & $\begin{array}{l}\text { DBPCRCT, } 24 \text { wk, } \\
11 \text { pts TSA subgroup }\end{array}$ & $\begin{array}{l}\text { Ada } 40 \mathrm{mg} \\
\text { qow vs } \\
\text { placebo }\end{array}$ & Ada: $0 \%$ \\
\hline
\end{tabular}

endpoint was the percentage of patients achieving an ASAS20 at 12 weeks. Secondary outcome measures included the ASAS20 response at week 24 and the ASAS40 response, ASAS5/6 response, and percentage of patients achieving partial remission at weeks 12 and 24. Early escape to openlabel adalimumab therapy was allowed for patients not achieving an ASAS20 at weeks 12, 16, or 20. At week 12, $58 \%$ of patients in the adalimumab group achieved an ASAS20 and response was documented as early as 2 weeks. Of the 74 placebo recipients that elected early escape, $>59 \%$ rapidly became ASAS20 responders at week 16 with adalimumab treatment. Comparatively, of the 81 patients who had previously received adalimumab during the double-blind portion of the study, almost $40 \%$ also became ASAS20 responders at week 16 with open-label adalimumab. The response rates for both groups increased over the remaining weeks. Furthermore, adalimumab-treated patients had significantly higher ASAS40, ASAS5/6, and partial remission responses at both time points compared with placebo.

Results were subsequently reported from a further open-label extension of the ATLAS study extended to 104 weeks (van der Heijde et al. 2007a). Of the initial trial patients, more than 55\% remained in the study. ASAS20 and ASAS40 response was preserved in the adalimumab group and a significant number of placebo patients who elected early escape at 24 weeks achieved an ASAS20 at both 52 and 104 weeks. Partial remission response also increased with adalimumab treatment from 22 to $39 \%$, indicating persistent improvement with continued treatment at 104 weeks.
As noted, the diagnosis of AS is often delayed. Some patients may already have substantial disease progression, for example bony ankylosis of the vertebrae, by the time they are referred for rheumatologic evaluation and treatment. Therefore, it is particularly noteworthy that a subset of patients with total spinal ankylosis (TSA) was included in the ATLAS study. Importantly, these patients still demonstrated improvement in ASAS responses. For this small percentage of patients, $50 \%$ (three of six) of the adalimumab-treated group achieved an ASAS20 response at week 12 compared with none of the patients receiving placebo. Figures improved to $66.7 \%$ of patients in the adalimumab-treated group at week 24, while the percentage of placebo patients responding remained at zero. These findings are noteworthy, indicating that AS patients with longstanding disease may also benefit from TNF-inhibitor therapy. The efficacy of adalimumab was also maintained in patients with TSA at 2 years (ASAS20 was achieved by $75 \%$ of patients) (van der Heijde et al. 2007a).

Adalimumab may also be beneficial in patients with early AS. In a recent placebo-controlled study, the diagnosis of early AS or preradiographic axial spondyloarthritis was defined as the presence of at least two of three clinical parameters, including inflammatory back pain, HLA-B27 positivity, and an MRI showing acute inflammation of the spine or sacroilitis (Haibel et al. 2007b). A total of 46 patients meeting these criteria were randomized to placebo or adalimumab biweekly for 12 weeks followed by an open-label extension. Patients treated with adalimumab had statistically significantly higher ASAS20 and ASAS40 scores at 12 weeks compared with placebo (68 and $55 \%$ versus 21 and $13 \%)$. Partial remission was also achieved in $>22 \%$ of adalimumab patients. Efficacy remained stable through week 20. In addition, $>70 \%$ of patients who originally received placebo achieved an ASAS20 after only 8 weeks of adalimumab treatment.

\section{Improvement in BASDAI}

The BASDAI is a well-established, reliable, and validated qualitative and quantitative method for determining disease activity in AS (Garratt et al. 1994). In earlier studies, the BASDAl was often assessed as a primary outcome. However, in adalimumab trials, it has largely been replaced by the ASAS criteria and is now frequently appraised as a secondary outcome.

Improvement in BASDAI (as a primary outcome) with adalimumab was documented in the initial open-label trial by Haibel et al. (2006a). Later, in the ATLAS study, BASDAI (as a secondary outcome measure) demonstrated significant and sustained improvement at 104 weeks in the adalimumab-treated patients compared with placebo (van der Heijde et al. 2007b).

\section{Quality of Life}

Familiar instruments for the assessment of QOL in AS patients include the Short Form 36 (SF-36) Health Survey and the Ankylosing Spondylitis Quality of Life Questionnaire (ASQoL). The SF-36 was originally developed for application in chronic disease populations and incorporates a Physical Component Summary 
(PCS) score and a Mental Component Summary (MCS) score. The PCS and MCS each include four domain scores including physical function, pain, general overall health, and social function (Davis et al. 2007). Both summary scores and domain scores have proven reliability and validity in AS populations (Dagfinrud et al. 2004). The ASQoL was developed specifically for AS patients to assess the current impact of AS on their QOL. The 18-item disease-specific questionnaire has exhibited sufficient construct validity and reliability in multiple studies (Haywood et al. 2003).

Health-related quality of life (HRQOL) measures in AS are important in assessing several areas of patient wellbeing including physical, psychologic, mental, and social. The impact of improvement in these outcomes is even greater when paralleled by significant improvements in clinical outcomes. In the ATLAS trial, HRQOL was measured by the SF-36 Health Survey at baseline, 12 weeks, and 24 weeks, and by the ASQoL questionnaire at baseline and weeks 2, 12, and 24 (Davis et al. 2007). Overall, adalimumab-treated patients had statistically significant improvements in SF-36 and ASQoL scores compared with placebo patients at week 12 (Table 4). These improvements occurred as early as 2 weeks after initiating treatment with adalimumab and persisted through week 24 . The improvements in $\mathrm{HRQOL}$ were considered clinically meaningful as the mean change from baseline in SF-36 scores at both 12 weeks and 24 weeks exceeded the a priori minimum important difference (MID) of three points for the adalimumab group but not for the placebo group. Furthermore, there was significant association between HRQOL improvements and ASAS clinical responses.

Adalimumab also improves physical functioning and work productivity in AS patients (van der Heijde et al. 2006a). After 24 weeks of treatment, patients receiving adalimumab reported greater improvement versus placebo in BASFI and SF-36 scores.

Table 4 | Effect of adalimumab on quality of life in patients with AS (Davis et al. 2007)

\begin{tabular}{llll}
\hline Design & Treatment & Outcome & Results \\
\hline DBPCRCT, & Ada $40 \mathrm{mg}$ qow vs & SF-36 PCS & 12 wk achieving a \\
$24 \mathrm{wk}, 315$ & placebo & & priori MID: \\
pts & & Ada: $65 \%$ \\
& & Placebo: $37.6 \%$ \\
& 24 wk: \\
& & Ada: $67.3 \%$ \\
& & Placebo: $39.6 \%$ \\
& & 12 wk achieving a \\
& & priori MID: \\
& & Ada: $59.6 \%$ \\
& & Placebo: $42.1 \%$ \\
& & 24 wk: \\
& & Ada: $65.4 \%$ \\
& & Placebo: $42.1 \%$ \\
& &
\end{tabular}

Ada, adalimumab; AS, ankylosing spondylitis; ASQoL, Ankylosing Spondylitis Quality of Life Questionnaire; DBPCRCT, double-blind placebo-controlled randomized clinical trial; MID, minimum important difference; PCS, physical component summary; pts, patients; qow, every other week; SF-36, short form-36; wk, week.
Work productivity, as measured by the Work Productivity and Activity Impairment-Specific Health Problem (WPAI-SHP) questionnaire, correlated significantly with these scores. In addition, duration of exposure to adalimumab and baseline disease activity BASDAI score were significant predictors of improvement of overall work productivity loss at week 24 from baseline.

\section{Improvements in MRI}

Clinical benefit in AS patients treated with adalimumab has been paralleled by improvements in spinal inflammation and sacroilitis assessed by MRI. Recently, a small study examined the effects of 6 months of adalimumab therapy on acute spinal changes in eight AS patients using the Ankylosing Spondylitis Spine MRI-a (ASspiMRI-a) scoring system (Carrasco et al. 2007). Results were compared with changes in clinical and biologic variables including CRP, BASFI, BASDAI, and patient and physician global assessments. Statistically significant improvement was documented in all variables except CRP. ASspiMRI-a median score was significantly lower than baseline after 24 weeks of adalimumab therapy.

A phase III trial examined the effects of adalimumab versus placebo by MRI on both spinal and sacroiliac joint inflammation in AS patients $(n=82)$ over a 52-week period (Maksymowych et al. 2006). Inflammation was measured by the Spondyloarthritis Research Consortium of Canada (SPARCC) MRI index. In the adalimumab-treated group, mean percent change in the SPARCC score of the spine and sacroiliac joints was -50 and $-52 \%$ at 52 weeks. After week 24, placebo patients were switched to open-label adalimumab and had improved SPARCC scores comparable to the adalimumab group by week 52 .

\section{Safety}

Adalimumab has shown an acceptable safety profile specifically in AS patients. In the ATLAS trial, adverse event rates per 100 patient years were compared at 24 weeks (double-blind phase) and after 2 years of adalimumab exposure (van der Heijde et al. 2007a). The rate of serious adverse events at the two time points was 10.2 and $10.5 \%$. At 24 weeks, there were no serious infections reported. This increased to a rate of only $1.1 \%$ at 2 years of treatment. Adverse events leading to discontinuation of the study did not increase significantly (3.8 and 4.5\%). After 104 weeks' treatment, adverse events occurring at a frequency of $5 \%$ or more included nasopharyngitis, upper respiratory tract infection, and headache. Of note, there were no cases of tuberculosis, lupus-like symptoms, demyelinating disease, or death during the 2-year study.

\section{Economic evidence}

The economic evidence for the use of adalimumab in AS is limited to the models summarized in a NICE technology appraisal (NICE 2007) and one analysis investigating the cost efficacy of adalimumab for treatment of AS in the UK (Botteman et al. 2007). 
The NICE technology appraisal includes a model from the manufacturer of adalimumab, and their own. The manufacturer's economic evaluation uses a patient-based transition-model, which compares the use of adalimumab plus NSAIDs versus treatment with NSAIDs alone. Patient-level data from the Canadian AS (Maksymowych et al. 2005) and the ATLAS (van der Heijde et al. 2006a) phase III trials were included, and helped to simulate treatment decisions based on the British Society for Rheumatology (BSR) guidelines. Unlike these recommendations, the study populations included patients who had responded inadequately to fewer than two NSAIDs. The model considered both short-term trial data for responders or nonresponders and long-term outcomes for adalimumab responders. In the shortterm component of the model, BASDAI and BASFI scores remained stable as long as the patients were treated with adalimumab. In contrast, BASFI scores of patients on standard therapy were assumed to increase by 0.05 units/year. Assumptions were made that discontinuation of adalimumab treatment would return BASDAI and BASFI scores to the average values of those patients in the model managed by conventional therapy, and that the discontinuation rate would be approximately $10 \%$ per year. Disease-specific costs were based on ordinary least squares (OLS) regression of BASDAI and BASFI data from OASIS (Boonen et al. 2003). Only BASDAI measurements were used to estimate costs in the base case analysis.

The incremental cost-effectiveness ratios (ICERs) varied from $£ 18000$ to around $£ 27000$ (over 30 years). Moreover, a BASFIbased scenario estimated the ICERs at £29 000 (5 years) and $£ 25300$ (10 years). The NICE Technology Assessment Group investigated the use of adalimumab, etanercept, and infliximab versus "conventional treatment" in a cohort of 1000 patients. The cost effectiveness of these interventions in the short term (1 year) and over a time horizon up to 20 years was estimated. The shortterm model used weekly cycles for its Markov-like transitions, and the long-term model (2-20 years) was based on quarterly cycles. They assumed that all three interventions were of equal effectiveness, and that the differences in costs were consequently driven by issues related to their relative acquisition and administration costs. The short-term model used the response rates from the pooled week 12 data from the adalimumab, etanercept, and infliximab trials. Several assumptions were made in terms of spontaneous recovery rate and annual TNF withdrawal number. As in the manufacturer's model, disease-related costs were based on OLS regression of BASDAI and BASFI data from OASIS. BASFI was used as the major predictor of costs. For the long-term estimations, the model explored two alternative scenarios for BASFI progression on treatment: BASFI progression continues while on TNF inhibitor treatment, and no increase in BASFI score while on treatment.

In the first year of treatment, the ICER in cost per quality-adjusted life-year (QALY) gained was approximately $£ 55000$ for adalimumab and etanercept, and the ICER for infliximab was over $£ 120000$. Due to the assumptions made by the Assessment Group regarding spontaneous recovery of patients given conventional therapy, cost estimations in the long-term modeling demonstrated steadily increasing ICERs from year 2 onwards.
However, multiway sensitivity analysis identified scenarios in which adalimumab/etanercept could be cost effective, with ICERs around $£ 20000$.

Botteman and colleagues (2007) evaluated the cost effectiveness of adalimumab versus conventional therapy in patients with active AS from the perspective of the NHS in the UK. The authors estimated direct medical costs and QALYs for three time periods, namely 48 weeks, 5 years, and 30 years. Indirect costs and other costs were considered in a separate scenario. The analysis was pooled on data from the ATLAS and the Canadian AS phase III trials. A microstimulation model was developed for the adalimumab group according to the International ASAS Consensus Statement and BSR guidelines. Using the pooled adalimumab data, as well as data from the OASIS database and the literature, they created a model to estimate patients' BASDAI and BASFI scores, costs, and HRQOL associated with various degrees of disease activity. Calculations (in 2004 £UK) were made from the perspective of the UK NHS regarding costs of drugs, administration, monitoring, hospitalization, and adverse events. All costs and benefits for economic and clinical outcomes were discounted at the rate of $3.5 \%$ per annum. The ICER per QALY of adalimumab versus conventional therapy was estimated to improve with longer time horizons, namely from £47083 (48 weeks) to £23 097 (30 years). Including indirect costs, the ICER improved to $£ 5093$ per QALY. The analysis suggests that adalimumab is cost effective for the treatment of AS according to BSR guidelines relative to conventional therapy from the perspective of the UK NHS.

\section{Resource utilization}

Truly effective therapeutic options for AS had been quite limited for a long time. Conventional treatment modalities may have had an effect on pain and other symptoms, but did not alter the progression of disease and had no effect on the spinal manifestations. The high efficacy of the expensive TNF blockers, including adalimumab, for the treatment of AS demonstrated a breakthrough for NSAIDrefractory patients. Despite their clinical efficacy, the relatively high acquisition costs of TNF inhibitors are of potential concern. As presented above, economic data on adalimumab in AS are limited, and its long-term effect on the burden of the disease is unknown. Long-term controlled trials are necessary to confirm the benefits of the anti-TNF therapy, particularly regarding the maintenance of improvements in functional status/QOL, the effect on disease progression, and, of course, safety. Moreover, adalimumab has also shown efficacy for extrarheumatic manifestations frequently occurring in patients with AS, such as psoriasis, Crohn's disease, and anterior uveitis (Kavanaugh et al. 2006). The notable clinical efficacy of adalimumab needs to be factored into a comprehensive assessment of value, particularly considering the fact that effectiveness and cost-effectiveness analyses of the TNF inhibitors mostly assessed AS-specific outcomes and did not fully capture any possible effects of treatment on nonskeletal manifestations of AS.

The cost efficacy of anti-TNF therapy will depend on whether treatment can alter the clinical course and avoid long-term disability. As demonstrated in the BeSt trial for early RA, early 
aggressive treatment with infliximab resulted in earlier functional improvement and less radiographic damage (Goekoop-Ruiterman et al. 2005, 2007), and the sequential or early use of TNF antagonists may also play an important role in the future for patients with AS. Diagnosing and treating AS patients earlier will be a major challenge for many clinicians and an important strategy for the prevention of long-term damage and loss of function. Future cost effectiveness and other analyses will be crucial to assess the optimal use of the newer therapies. It will be important that the models used focus on the drug's effect on direct and indirect costs, and particularly on productivity and employability in patients with AS. Additional health economic implications may play a role in the future, when more anti-TNF agents could be brought to the clinic. The introduction of additional agents combined with market forces may help lower their costs.

\section{Patient group/population}

Adalimumab is currently approved by the FDA for the treatment of adult patients with chronic severe AS who have inadequate response to conventional therapy. International criteria for the use of TNF inhibitors in AS were recently updated (Braun et al. 2006b) and recommended the following revisions for the initiation of antiTNF treatment: a diagnosis of definitive AS (based on the modified New York criteria) and active disease for at least 4 weeks as defined by a sustained BASDAI $\geq 4$ on a $0-10$ scale and expert opinion based on clinical findings; refractory disease, defined by failure of $\geq 2$ NSAIDs during a 3-month period, failure of intraarticular steroids (if indicated), and failure of sulfasalazine in patients with predominantly peripheral arthritis; and application of the usual precautions and contraindications for biologic treatment. Guidelines for monitoring anti-TNF treatment were also updated and recommended that both the ASAS score set for clinical practice and the BASDAI should be followed after the initiation of treatment. Discontinuation of anti-TNF treatment in nonresponders should be considered after 6-12 weeks. Lastly, response would be defined by improvement of at least $50 \%$ or 2 units (on a 0-10 scale) of the BASDAI (Braun et al. 2006b). In the UK, guidelines for the use of TNF inhibitors from the BSR include only etanercept and infliximab (Keat et al. 2005), although the BSR has approved the use of adalimumab for patients with active AS under these guidelines (Anon. 2006). NICE recommends adalimumab for treatment of $A S$ if the patient satisfies the modified New York criteria, has a BASDAI score $\geq 4$ and a score of $\geq 4 \mathrm{~cm}$ on the spinal pain VAS demonstrated on two occasions at least 12 weeks apart, and in whom conventional treatment with maximum tolerated or recommended dosages of two or more NSAIDs has failed to control symptoms (NICE 2007).

Adalimumab was the first TNF antagonist to be tested in, and has demonstrated clinical efficacy in, patients with so-called "preradiographic axial spondyloarthritis" (Haibel et al. 2007b). A substantial number of these patients achieved partial remission, indicating that TNF inhibitors such as adalimumab may be more effective in patients with early disease and shorter disease duration. It has also been observed that patients with elevated CRP or greater amounts of inflammation on MRI may respond better to TNF inhibitors (Maksymowych et al. 2006; van der Heijde et al. 2006b). At the other end of the spectrum, analysis of data from studies of adalimumab has shown that TNF-inhibitor therapy can show important clinical benefit even in patients with total spinal ankylosis (van der Heijde et al. 2007b).

Few studies have examined the effects of adalimumab on extraarticular manifestations in AS. A recent retrospective study reported that treatment with adalimumab can reduce the number of uveitis flares in AS patients (Guignard et al. 2006). Another study evaluating the effects of adalimumab therapy on the prevention of relapse of inflammatory bowel disease showed an improved odds ratio compared with etanercept, but not infliximab (Braun et al. 2007). However, due to the small number of adalimumab patients analyzed in this study, final conclusions on this matter cannot be stated until further investigations are undertaken.

\section{Dosage, administration, and formulations}

Adalimumab (Humira) is a recombinant, human IgG1 monoclonal antibody, indicated for the treatment of $A S$ in adults aged $\geq 18$ years. It is available as a sterile, preservative-free solution of $40 \mathrm{mg}$ per $0.8 \mathrm{~mL}$ in $1.0 \mathrm{~mL}$, prefilled, single-use syringes, or in a pen. If refrigerated, it has a shelf life of 18 months. The needle cover of the prefilled syringe and the pen contain dry natural rubber, so patients with latex allergies should avoid using adalimumab (Anon. 2007).

The recommended starting dose is $40 \mathrm{mg}$ injected subcutaneously every other week (i.e. every 14 days). This dose can be increased to every week if response is deemed inadequate. Treatment should be continued up to 12 weeks and discontinued if the patient does not meet treatment response criteria at that time. Concomitant treatment with methotrexate or other DMARDs is not required for efficacy.

Patients are encouraged to self-administer adalimumab. Common injection sites include the thighs, outer arms, and abdomen. Injection sites should be cleaned with alcohol prior to injection and should not be given at the same site consecutively. Areas where the skin is scarred, inflamed, or broken should be avoided.

\section{Place in therapy}

Although few in number, clinical trials have established the efficacy of adalimumab in the treatment of AS up to 104 weeks. Significant improvements compared with placebo have been documented as early as 2 weeks in both physician-assessed and patient-assessed outcomes. Substantial decreases in primary and secondary endpoints such as the BASDAI, ASAS20, ASAS40, ASAS5/6, and partial remission response criteria have suggested that the benefit achieved with adalimumab is at least comparable to that seen with etanercept and infliximab. Adalimumab is also effective for peripheral arthritis, enthesitis, and extraarticular manifestations associated with AS, including uveitis and inflammatory bowel disease. In addition, adalimumab has an acceptable safety profile in AS patients. 
Perhaps clinically the most important are the effects of adalimumab on the AS patient's QOL. In clinical trials, adalimumab significantly impacted patient QOL when assessed by both a disease-specific (ASQoL) and a generic health status instrument (SF-36). Studies have also shown that there is a significant correlation between improvements in HRQOL and ASAS clinical responses. Other parameters that improved with adalimumab included overall emotional health and fatigue.

Current guidelines recommend adalimumab for the treatment of severe, active AS. Some evidence from studies of adalimumab suggests that patients in the early stages of disease or preradiographic AS have a greater response rate to TNF inhibitors than patients with established AS. Therefore, earlier diagnosis of AS may become critical if treatment with biologic therapy proves to have significant effects on future disease progression. Furthermore, adalimumab has shown efficacy in patients with complete ankylosis of the spine. These patients were previously thought to obtain little benefit from further treatment. Currently, international criteria do not recommend treatment with biologics for patients with TSA, but modification of future standards are expected to recognize this subset of patients.

Additionally, patients with elevated CRP or ESR or greater amounts of inflammation on MRI may also exhibit a more profound response to adalimumab, especially earlier in the disease course. The extent to which suppression of inflammation on MRI correlates with attenuation of structural damage as measured by plain radiography remains to be elucidated.

Recent European analysis suggests that adalimumab is a costeffective treatment for AS compared with conventional therapy. However, high acquisition costs remain a concern. Economic data on adalimumab use in AS are limited and its long-term effect on the burden of disease is unknown. Supplementary information from further controlled trials, particularly regarding the maintenance of improvements in functional status and QOL, structural progression, and safety will also have be addressed in future calculations of cost effectiveness.

\section{Acknowledgments}

\author{
Dr Kavanaugh has conducted clinical research sponsored \\ by Abbott.
}

\section{References}

Anderson JJ, Baron G, van der Heijde D, Felson DT, Dougados M. Ankylosing Spondylitis assessment group preliminary definition of short-term improvement in ankylosing spondylitis. Arthritis Rheum. 2001;44:1876-1886.

Anon. Ankylosing Spondylitis Prescribing Information. Humira. 2007. Available at: http://www.humira.com/AnkylosingSpondylitis/Default.aspx (accessed September 22, 2007).

Anon. Clinical Guidelines: Ankylosing Spondylitis. BSR Statement on Adalimumab for Ankylosing Spondylitis. The British Society of Rheumatology. August 2006. Available at: www.rheumatology.org.uk/guidelines/guidelines_as (accessed September 22, 2007).
Baraliakos X, Listing J, Brandt J, et al. Clinical response to discontinuation of anti-TNF therapy in patients with ankylosing spondylitis after 3 years of continuous treatment with infliximab. Arthritis Res Ther. 2005;7:439-444.

Boonen A. A review of work-participation, cost-of-illness and cost-effectiveness studies in ankylosing spondylitis. Nat Clin Pract Rheumatol. 2006;2:546-553.

Boonen A, van der Heijde D, Landewé R, et al. Direct costs of ankylosing spondylitis and its determinants: an analysis among three European countries. Ann Rheum Dis. 2003;62:732-740.

Botteman MF, Hay JW, Luo MP, et al. Cost effectiveness of adalimumab for the treatment of ankylosing spondylitis in the United Kingdom. Rheumatology. 2007:46:1320-1328 (advance access publication June 2007).

Brandt J, Khariouzov A, Listing J, et al. Six-month results of a double-blind, placebo-controlled trial of etanercept treatment in patients with active ankylosing spondylitis. Arthritis Rheum. 2003;48:1667-1675.

Brandt J, Listing J, Sieper J, et al. Development and preselection of criteria for short term improvement after anti-TNF alpha treatment in ankylosing spondylitis. Ann Rheum Dis. 2004;63:1438-1444.

Braun J, Zochling J, Baraliakos X, et al. Efficacy of sulfasalazine in patients with inflammatory back pain due to undifferentiated spondyloarthritis and early ankylosing spondylitis: a multicentre randomised controlled trial. Ann Rheum Dis. 2006a;65:1147-1153.

Braun J, Davis J, Dougados M, et al. First update of the international ASAS consensus statement for the use of anti-TNF agents in patients with ankylosing spondylitis. Ann Rheum Dis. 2006b;65:316-320.

Braun J, Baraliakos X, Listing J, et al. Differences in the incidence of flares or new onset of inflammatory bowel diseases in patients with ankylosing spondylitis exposed to therapy with anti-tumor necrosis factor alpha agents. Arthritis Rheum. 2007;57:639-647.

Calin A, Garratt S, Whitelock H, et al. A new approach to defining functional ability in ankylosing spondylitis: the development of the Bath Ankylosing Spondylitis Functional Index. J Rheumatol. 1994;21:2281-2285.

Carrasco JA, Martos J, Guijo V, et al. Adalimumab achieve significant improvement in active ankylosing spondylitis patients assessed by magnetic resonance imaging. Ann Rheum Dis. 2007;66:391.

Chen J, Liu C. Is sulfasalazine effective in ankylosing spondylitis? A systematic review of randomized controlled trials. J Rheumatol. 2006;33:722-731.

Chen J, Liu C, Lin J. Methotrexate for ankylosing spondylitis. Cochrane Database Syst Rev. 2006;4:CD004524.

Chorus AM, Miedema HS, Boonen A, Van Der Linden S. Quality of life and work in patients with rheumatoid arthritis and ankylosing spondylitis of working age. Ann Rheum Dis. 2003;62:1178-1184.

Clegg DO, Reda DJ, Abdellatif M. Comparison of sulfasalazine and placebo for the treatment of axial and peripheral articular manifestations of the seronegative spondyloarthropathies: a Department of Veterans Affairs cooperative study. Arthritis Rheum. 1999;42:2325-2329.

Dagfinrud H, Mengshoel AM, Hagan KB, et al. Health status of patient with ankylosing spondylitis: a comparison with the general population. Ann Rheum Dis. 2004;63:1605-1610.

Davis J, Revicki D, van der Heijde D, et al. Health-related quality of life outcomes in patients with active ankylosing spondylitis treated with adalimumab: results from a randomized controlled study. Arthritis Rheum. 2007;57:1050-1057.

Feltkamp TE, Mardjuadi A, Huang F, Chou CT. Spondyloarthropathies in eastern Asia. Curr Opin Rheumatol. 2001;13:285-290.

Garrett S, Jenkinson T, Kennedy LG, Whitelock H, Gaisford P, Calin A. A new approach to defining disease status in ankylosing spondylitis: the Bath Ankylosing Spondylitis Disease Activity Index. J Rheumatol. 1994;21:2286-2291.

Goekoop-Ruiterman YP, de Vries-Bouwstra JK, Allaart CF, et al. Clinical and radiographic outcomes of four different treatment strategies in patients with early rheumatoid arthritis (the BeSt study): a randomized, controlled trial. Arthritis Rheum. 2005;52:3381-3390.

Goekoop-Ruiterman YP, de Vries-Bouwstra JK, Allaart CF, et al. Comparison of treatment strategies in early rheumatoid arthritis: a randomized trial. Ann Intern Med. 2007;146:406-415. 
Guignard S, Gossec L, Salliot C, et al. Efficacy of tumour necrosis factor blockers in reducing uveitis flares in patients with spondylarthropathy: a retrospective study. Ann Rheum Dis. 2006;65:1631-1634.

Haibel H, Rudwaleit M, Braun J, Sieper J. Six months open label trial of leflunomide in active ankylosing spondylitis. Ann Rheum Dis. 2005;64:124-126.

Haibel $\mathrm{H}$, Rudwaleit M, Brandt $\mathrm{HC}$, et al. Adalimumab reduces spinal symptoms in active ankylosing spondylitis: clinical and magnetic resonance imaging results of a fifty-two-week open-label trial. Arthritis Rheum. 2006a;54:678-681.

Haibel H, Brandt HC, Baraliakos X, et al. Long-term efficacy and safety of adalimumab in the treatment of active ankylosing spondylitis: results of an open-label, 2-year trial. Ann Rheum Dis. 2006b;65:218.

Haibel $\mathrm{H}$, Brandt $\mathrm{HC}$, Song $\mathrm{IH}$, et al. No efficacy of subcutaneous methotrexate in active ankylosing spondylitis: a 16-week open-label trial. Ann Rheum Dis. 2007a;66:419-421.

Haibel H, Rudwaleit M, Amtenbrink A, et al. Efficacy of adalimumab in the treatment of preradiographic axial spondylarthritis: results of a 20-week, randomized controlled trial with an open-label extension phase. Ann Rheum Dis. 2007b;66:64.

Haywood KL, Garratt AM, Dziedzic K, Dawes PT. Patient centered assessment of ankylosing spondylitis-specific health related quality of life: evaluation of the Patient Generated Index. J Rheumatol. 2003;30:764-773.

Huang F, Wei JC, Breban M. Thalidomide in ankylosing spondylitis. Clin Exp Rheumatol. 2002;20(Suppl. 28):S158-S161.

Jenkinson TR, Mallorie PA, Whitelock HC, Kennedy LG, Garrett SL, Calin A. Defining spinal mobility in ankylosing spondylitis (AS). The Bath AS Metrology Index. J Rheumatol. 1994;21:1694-1698.

Kavanaugh A, Tutuncu Z, Catalan-Sanchez T. Update on anti-tumor necrosis factor therapy in the spondyloarthropathies including psoriatic arthritis. Curr Opin Rheumatol. 2006;18:347-353.

Keat A, Barkham N, Bhalla A, et al. BSR guidelines for prescribing TNF-a blockers in adults with ankylosing spondylitis. Report of a working party of the British Society for Rheumatology. Rheumatology (Oxford). 2005;44:939-947.

Khan MA. Update on spondyloarthritis. Ann Intern Med. 2002;136:896-907.

Kirwan J, Edwards A, Huitfeldt B, Thompson P, Currey H. The course of established ankylosing spondylitis and the effects of sulphasalazine over 3 years. Br J Rheumatol. 1993;32:729-733.

Lewis SC, Langman MJ, Laporte JR, et al. Dose-response relationships between individual nonaspirin nonsteroidal anti-inflammatory drugs (NANSAIDs) and serious upper gastrointestinal bleeding: a meta-analysis based on individual patient data. Br J Clin Pharmacol. 2002;54:320-326.

Maksymowych WP, Jhangri GS, Fitzgerald AA, et al. A six-month randomized, controlled, double-blind, dose-response comparison of intravenous Pamidronate $(60 \mathrm{mg}$ versus $10 \mathrm{mg})$ in the treatment of nonsteroidal antiinflammatory drug-refractory ankylosing spondylitis. Arthritis Rheum. 2002;46:766-773.

Maksymowych WP, Rahman P, Keystone E, et al. Efficacy of adalimumab in active ankylosing spondylitis (AS) - results of the Canadian AS study. Arthritis Rheum. 2005;52:505.

Maksymowych WP, Lambert RGW, Salonen D, et al. Adalimumab reduces spinal and sacroiliac joint inflammation in patients with ankylosing spondylitis (AS) - 52 week magnetic resonance imaging (MRI) results from the Canadian AS study. Ann Rheum Dis. 2006;65:65.
NICE (National Institute for Health and Clinical Excellence). Adalimumab, etanercept and infliximab for ankylosing spondylitis: final appraisal determination. National Institute for Health and Clinical Excellence, 2007. Available at: http://www.nice.org.uk/nicemedia/pdf/ASFADfinal.pdf (accessed November 7, 2007).

Rudwaleit M, Listing J, Brandt J, Braun J, Sieper J. Prediction of a major clinical response (BASDAI 50) to tumour necrosis factor alpha blockers in ankylosing spondylitis. Ann Rheum Dis. 2004;63:665-670.

Sieper J, Rudwaleit M, Khan MA, Braun J. Concepts and epidemiology of spondyloarthritis. Best Pract Res Clin Rheumatol. 2006;20:401-417.

Solomon SD, McMurray JJV, Pfeffer MA, et al. Cardiovascular risk associated with celecoxib in a clinical trial for colorectal adenoma prevention. $\mathrm{NEngl} \mathrm{J}$ Med. 2005;352:1071-1080.

van Denderen JC, van der Paardt M, Nurmohamed MT, et al. Double blind, randomised, placebo controlled study of leflunomide in the treatment of active ankylosing spondylitis. Ann Rheum Dis. 2005;64:1761-1764.

van der Heijde D, Dougados M, Davis J, et al. ASsessment in Ankylosing Spondylitis International Working Group/Spondylitis Association of America recommendations for conducting clinical trials in ankylosing spondylitis. Arthritis Rheum. 2005;52:386-394.

van der Heijde D, Luo MP, Wordsworth P, et al. Adalimumab improves physical functioning and work productivity in ankylosing spondylitis (AS) patients: Results from ATLAS. Arthritis Rheum. 2006a;54:99.

van der Heijde D, Kivitz A, Schiff M, et al. Efficacy and safety of adalimumab in patients with ankylosing spondylitis: results from a multicenter, randomized, double-blind, placebo-controlled trial. Arthritis Rheum. 2006b;54:2136-2146. van der Heijde D, Schiff M, Sieper J, et al. Adalimumab treatment maintains efficacy and safety in patients with ankylosing spondylitis (AS) - 2-year results from ATLAS. Ann Rheum Dis. 2007a;66(Suppl. II):411.

van der Heijde D, Schiff M, Braun J, et al. Adalimumab is effective in reducing signs and symptoms in ankylosing spondylitis patients with total spinal ankylosis - results from ATLAS. Ann Rheum Dis. 2007b;66(Suppl. II):412.

van Tubergen A, Landewé R, van der Heijde D, et al. Combined spa-exercise therapy is effective in patients with ankylosing spondylitis: a randomized controlled trial. Arthritis Rheum. 2001;45:430-438.

Wei JC, Chan TW, Lin H, Huang F, Chou CT. Thalidomide for severe refractory ankylosing spondylitis: a 6-month open-label trial. $J$ Rheumatol. 2003;30:2627-2631.

Zochling J, Braun J. Remission in Ankylosing Spondylitis. Clin Exp Rheumatol. 2006;24(Suppl. 43):S88-S92.

Zochling J, van der Heijde D, Dougados M, et al. Current evidence for the management of ankylosing spondylitis: a systematic literature review for the ASAS/EULAR management recommendations in ankylosing spondylitis. Ann Rheum Dis. 2006a;65:423-432.

Zochling J, Bohl-Bühler MH, Baraliakos X, Feldtkeller E, Braun J. Nonsteroidal anti-inflammatory drug use in ankylosing spondylitis--a population-based survey. Clin Rheumatol. 2006b;25:794-800.

Correspondence: Arthur Kavanaugh, MD, Professor of Medicine and Director, Center for Innovative Therapy, Division of Rheumatology, Allergy and Immunology, University of California, San Diego, 9500 Gilman Drive, Mail Code 0943, La Jolla, CA 92093-0943, US or at akavanaugh@ucsd.edu 